\title{
Electrochemical characterization of mechanically alloyed LaCaMgNig compound
}

\author{
S. Chebab ${ }^{1} \cdot$ M. Abdellaoui ${ }^{1} \cdot$ M. Latroche $^{2} \cdot$ V. Paul-Boncour ${ }^{2}$
}

Received: 25 November 2015/Accepted: 8 June 2016/Published online: 16 July 2016

(c) The Author(s) 2016. This article is published with open access at Springerlink.com

\begin{abstract}
The performance of a nickel-metal hydride ( $\mathrm{Ni}$ $\mathrm{MH})$ battery mainly depends on the characteristics of the negative electrode. The electrochemical characteristics of mechanically alloyed compound $\mathrm{LaCaMgNi}_{9}$, including the discharge capacity and the hydrogen diffusion coefficient, were studied as function of mechanical alloying (MA) conditions. The electrochemical measurements show that the $\mathrm{LaCaMgNi}_{9}$ electrode has a maximum discharge capacity of about $150 \mathrm{mAh} / \mathrm{g}$ at a discharge rate of $\mathrm{C} / 3$. The hydrogen discharge capacity dramatically decreases as MA duration exceeds $20 \mathrm{~h}$.
\end{abstract}

Keywords $\mathrm{AB}_{3}$-type alloy · Mechanical alloying · Electrochemical characteristics

\section{Introduction}

Hydrogen is considered as a promising sustainable energy carrier due to its high energy density and the fact that it can be produced from a variety of renewable sources including biomass and water electrolysis. In addition, hydrogen combustion does not emit green-house gases to the atmosphere which justifies its classification as a clean source of energy. To be able to use hydrogen as an energy source, its

\section{S. Chebab}

chebabsafa14@gmail.com

1 Laboratoire des matériaux Utiles, Institut National de Recherche et d'Analyses Physico-chimique, Pole technologique de Sidi Thabet, 2020 Sidi Thabet, Tunisia

2 ICMPE-CMTR; CNRS-UPEC, 2-8 rue Henri Dunant, 94320 Thiais Cedex, France safe and efficient storage is a key requirement, but has remained a most challenging issue [1].

Hydrogen storage alloys have been extensively studied for many years as negative electrode materials of $\mathrm{Ni}-\mathrm{MH}$ batteries [2-6]. Among the various kinds of hydrogen storage materials for $\mathrm{Ni}-\mathrm{MH}$ batteries, the $\mathrm{AB}_{5}$-type compounds display an average maximum discharge capacity of $300 \mathrm{mAh} / \mathrm{g}$. However, none of the currently commercialized electrode alloys, including $\mathrm{AB}_{5}$ and $\mathrm{AB}_{2}$-types, can meet the demand of power battery owing to the limitation of their properties, such as low discharge capacity for the $\mathrm{AB}_{5^{-}}$ type compounds and poor activation capability for the $\mathrm{AB}_{2^{-}}$ type Laves phase electrode alloy. Therefore, one of the main challenges in this area is to find new type of electrode materials with higher capacity and longer cycle life.

In the recent years, $\mathrm{La}-\mathrm{Mg}-\mathrm{Ni}$ hydrogen storage alloys, with $\mathrm{PuNi}_{3}$-type structure, have been considered as promising candidates owing to the benefit of lower cost, higher discharge capacity and good electrochemical properties compared to $\mathrm{AB}_{5}$-type alloys [7-11].

Kadir et al. [11, 12] revealed that $R \mathrm{Mg}_{2} \mathrm{Ni}_{9}(R=$ rare earth, $\mathrm{Ca}$ or $\mathrm{Y}$ ) alloys keep the $\mathrm{PuNi}_{3}$-type rhombohedral structure after hydriding, and that their hydrogen storage capacity, which could reach 1.7-1.8\% (mass fraction), was significantly higher than that of the mischmetal-based $\mathrm{AB}_{5^{-}}$ type alloys.

Chen et al. [7] have prepared by induction melting several kinds of $\mathrm{R}-\mathrm{Mg}-\mathrm{Ni}$ based alloys with $\mathrm{PuNi}_{3}$-type structure. Subsequently, they found that the discharge capacity of $\mathrm{LaCaMgNi}_{9}$ alloy could reach $360 \mathrm{mAh} / \mathrm{g}$ (1.87 wt $\%)$, but the high-rate dischargeability and cyclic stability were poor.

In this work, $\mathrm{LaCaMgNi}_{9}$ compound was prepared by mechanical alloying (MA) to avoid inherent problems of the melting techniques [13]. It is now established that MA 
is an efficient process to synthesize a wide variety of equilibrium and non-equilibrium structures in solid state. The synthesized alloys exhibit a good compositional and microstructural homogeneity with nanometric sized particles due to the high energy impact during milling. Nanostructuring is one of the possible approaches to improve the hydrogenation properties of these materials $[14,15]$. The aim of this work was to study the nanostructuring effect on the electrochemical properties of LaCaMgNi, -type alloy.

\section{Experimental details}

Elemental $\mathrm{La}, \mathrm{Ca}, \mathrm{Mg}$ and $\mathrm{Ni}$ powders (with at least $99.9 \%$ purity) were mixed with the nominal composition $\mathrm{LaCaMgNi}_{9}$ and charged into carbide vials under controlled atmosphere (purified argon in glove box). MA was performed with a Fritsch Pulverisette P7 planetary ball mill at a rotation speed of $400 \mathrm{rpm}$ with a ball to powder ratio equal to $17: 1$. The MA duration was varied from 4 to $30 \mathrm{~h}$ and the samples were labeled $\mathrm{Sd}$ ( $\mathrm{S}$ for sample and $\mathrm{d}$ for duration in hour).

Each powdered sample was sieved to a particle size below $40 \mu \mathrm{m}$ for X-ray powder diffraction (XRD) analysis. XRD patterns were recorded with a $(\theta-2 \theta)$ Panaltytical $\mathrm{X}$ 'Pert pro MPD diffractometer with a copper anti-cathode $\left(\lambda_{\mathrm{CuK} \alpha}=0.15406 \mathrm{~nm}\right)$ in a $2 \theta$ range of $10^{\circ}-100^{\circ}$. The XRD data were analyzed by the Rietveld method [16, 17] using FULLPROF program [18].

Working electrodes were prepared by mixing the alloy powders with black carbon and PTFE in, respectively, 90, 5 and $5 \%$ weight proportions. Electrochemical measurements were performed in a conventional three-electrode open-air cell using a VMP biologic potentiostat-galvanostat. The discharge capacities of the electrodes were determined at room temperature by galvanostatically charge-discharge at, respectively, $\mathrm{C} / 3$ and $\mathrm{C} / 6$ rates. The $\mathrm{Ni}(\mathrm{OH})_{2} / \mathrm{NiOOH}$ and $\mathrm{Hg} / \mathrm{HgO}$ electrodes were used as the counter and the reference electrodes, respectively. Cyclic voltammetry was performed for different scan rates in the -0.5 to $-1.1 \mathrm{~V}$ potential range. The chronoamperometry was applied after 30 cycles of charge-discharge. This method consists in fully charging the electrode and discharging it at constant potential $(-0.6 \mathrm{~V}$ versus $\mathrm{Hg} / \mathrm{HgO})$.

\section{Experimental results and discussion}

\section{Structural properties of the alloys}

Starting from elemental $\mathrm{La}, \mathrm{Ca}, \mathrm{Mg}$ and $\mathrm{Ni}$ metals, MA leads to the formation of a mixture of nanocrystalline $A B^{-}$ type phase with $\mathrm{PuNi}_{3}$-type structure (S.G: $R-3 \mathrm{~m}$ ) and $\mathrm{LaNi}_{5}$ phase since $10 \mathrm{~h}$ of MA.

Figure 1 gives the XRD patterns of the samples alloyed for different times. In the XRD pattern of the un-milled sample (S0), all the diffraction lines of the starting elements are present. The diffraction peaks of nickel are the most intense while those of the other elements are barely detectable. This fact is mainly related to the low contents of $\mathrm{Ca}, \mathrm{Mg}$ and $\mathrm{La}$ (5.47, 3.32 and $18.9 \mathrm{wt} \%$, respectively) as compared to the $\mathrm{Ni}$ one (72.21 wt\%).

$\mathrm{X}$-ray diffraction patterns of the mechanically alloyed powders reveal a modification of the microstructure of the powders during MA process. With increasing MA duration, the originally sharp diffraction lines of the powders show a remarkable line broadening and an intensity reduction compared to the S0 sample. This indicates the decrease of the crystallite size and the presence of lattice microstrain within the particles. Furthermore, MA for long time results in the partial amorphization of the alloy. In fact, the increase of MA duration induces more strains and increases the defect concentration in the crystalline structure of elemental powders that leads to the destabilization of part of them into amorphous phase.

As we can see, Ni remains up to $20 \mathrm{~h}$ of MA while other elements are not observed after the first hours of milling. Depending on MA duration, the formation of an $\mathrm{AB}_{3}$-type phase with a $\mathrm{PuNi}_{3}$-type structure occurred in coexistence with $\mathrm{LaNi}_{5}$ (S.G: $\mathrm{P6} / \mathrm{mmm}$ ). The $\mathrm{LaNi}_{2}$-type phase appears as an intermediate phase for MA duration ranging from 4 to $8 \mathrm{~h}$ and disappears hereafter.

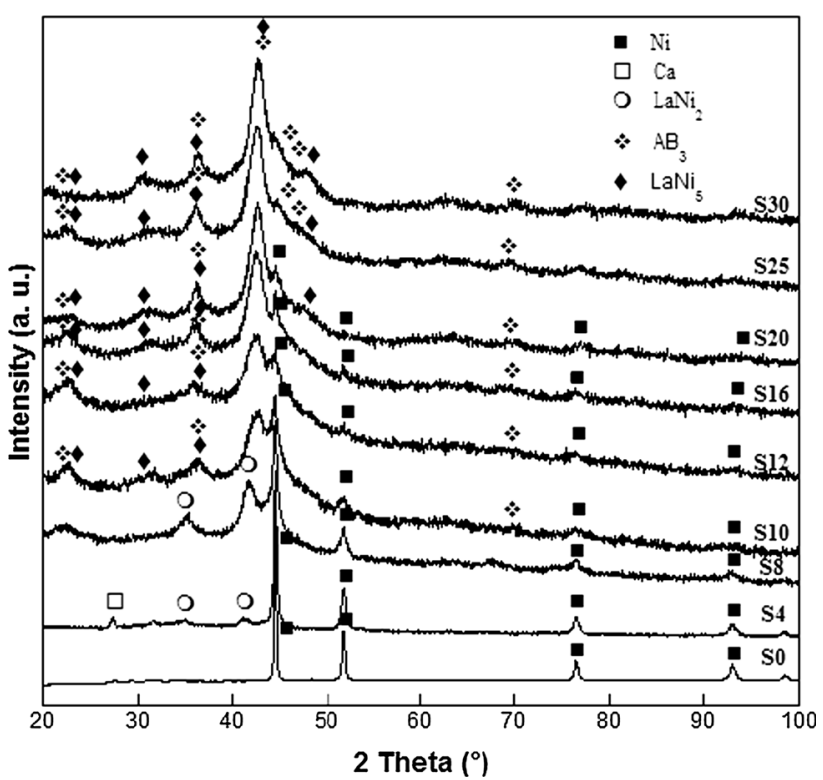

Fig. 1 Evolution of the XRD patterns of samples for increasing MA duration $(4-30 \mathrm{~h})$ 
Table 1 Phase structural properties and maximum discharge capacities of the samples synthesized by MA at various milling time

\begin{tabular}{|c|c|c|c|c|c|c|}
\hline $\begin{array}{l}\text { Sample } \\
\text { St }\end{array}$ & Phase & $\begin{array}{l}\text { Space } \\
\text { group }\end{array}$ & $\begin{array}{l}\text { Phase abundance } \\
\text { (wt } \% \text { ) }\end{array}$ & $\begin{array}{l}C_{\max }(\mathrm{mAh} / \mathrm{g} \\
\text { of active material })\end{array}$ & $\begin{array}{l}C_{10}(\mathrm{mAh} / \mathrm{g} \\
\text { of active material })\end{array}$ & $\begin{array}{l}\text { Loss of charge after } \\
\text { ten cycles }(\%)\end{array}$ \\
\hline \multirow[t]{3}{*}{ S10 } & $\mathrm{AB}_{3}$ & $R-3 m$ & 42.7 (1.6) & 130.4 & 107.8 & 17.3 \\
\hline & $\mathrm{LaNi}_{5}$ & $P 6 / \mathrm{mmm}$ & $40.1(1.4)$ & & & \\
\hline & $\mathrm{Ni}$ & $F m-3 m$ & $17.2(0.7)$ & & & \\
\hline \multirow[t]{3}{*}{ S12 } & $\mathrm{AB}_{3}$ & $R-3 m$ & $48.4(1.5)$ & 124.9 & 120.2 & 3.51 \\
\hline & $\mathrm{LaNi}_{5}$ & P6/mmm & 40.9 (1.3) & & & \\
\hline & $\mathrm{Ni}$ & $F m-3 m$ & $10.7(0.6)$ & & & \\
\hline \multirow[t]{3}{*}{ S16 } & $\mathrm{AB}_{3}$ & $R-3 m$ & $49.8(1.3)$ & 141.3 & 122.1 & 12.7 \\
\hline & $\mathrm{LaNi}_{5}$ & P6/mmm & $45.6(1.2)$ & & & \\
\hline & $\mathrm{Ni}$ & $F m-3 m$ & $4.6(0.5)$ & & & \\
\hline \multirow[t]{3}{*}{ S20 } & $\mathrm{AB}_{3}$ & $R-3 m$ & $52.2(1.4)$ & 156.1 & 117.1 & 24.2 \\
\hline & $\mathrm{LaNi}_{5}$ & P6/mmm & $43.1(1.2)$ & & & \\
\hline & $\mathrm{Ni}$ & $F m-3 m$ & $4.7(0.5)$ & & & \\
\hline \multirow[t]{2}{*}{ S25 } & $\mathrm{AB}_{3}$ & $R-3 m$ & $53.5(1.7)$ & 138.2 & 121.5 & 11.8 \\
\hline & $\mathrm{LaNi}_{5}$ & P6/mmm & $46.5(1.3)$ & & & \\
\hline \multirow[t]{2}{*}{ S30 } & $\mathrm{AB}_{3}$ & $R-3 m$ & 67 (1.8) & 121.6 & 95.4 & 21.2 \\
\hline & $\mathrm{LaNi}_{5}$ & P6/mmm & $33(1.2)$ & & & \\
\hline
\end{tabular}

The composition and lattice parameters of the phases were calculated by the Rietveld method and are listed in Table 1. As the MA duration increases, the abundance of the $\mathrm{LaCaMgNi}_{9} \mathrm{AB}_{3}$-type phase increases from about 43-63 wt $\%$ whereas that of $\mathrm{LaNi}_{5}$ increases first from 40 to $47 \mathrm{wt} \%$ and then decreases to $36 \mathrm{wt} \%$.

The SEM micrograph presented in Fig. 2 shows the morphology of the S30 sample. The powder is composed of large agglomerates of more than $5 \mu \mathrm{m}$ in size. These agglomerates are made of several smaller $(0.1-1 \mu \mathrm{m})$ deformed particles welded together.

\section{Electrochemical characterizations}

\section{Activation and charge-discharge cycle stability of the alloys}

The variation of the measured discharge capacities of the mechanically alloyed samples as a function of the chargedischarge cycle number is shown in Fig. 3. For all samples, the maximum discharge capacity was reached at the first cycle, then slightly decreases for next cycles to remain stable at higher cycle number. This decrease is due to the corrosion of the active phase in the electrolyte during the reaction.

As the alloy contains some phases that do not absorb hydrogen, the discharge capacity of the active material ( $C_{\text {activematerial, }}$ Table 1) was calculated based on the measured discharge capacity of the hole material (Fig. 3) and the contributions of the hydrogen absorbing phases only $\left(\mathrm{AB}_{3}\right.$-type and $\mathrm{LaNi}_{5}$ phases), as:

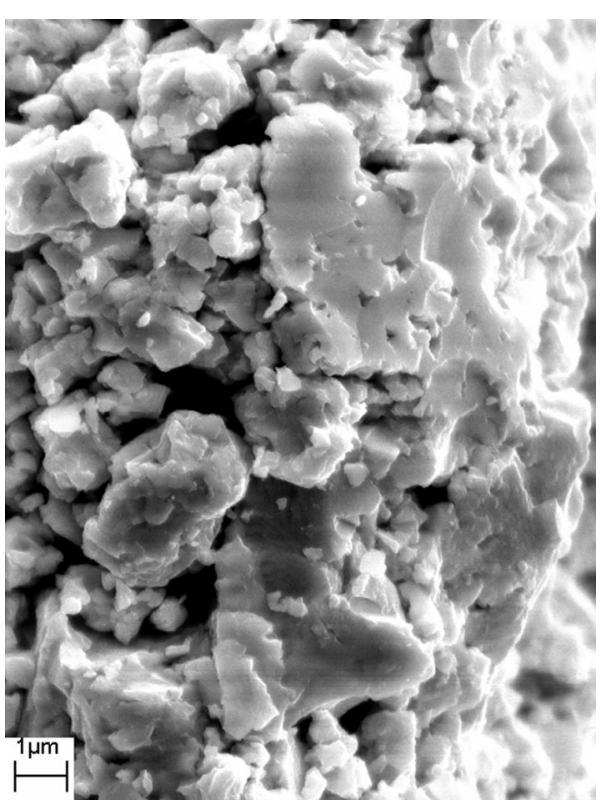

Fig. 2 SEM micrography showing the morphology of the S30 sample

$C_{\text {activematerial }}=C_{\text {measured }} /(x+y)$

where $C_{\text {measured }}$ is the measured discharge capacity (of the whole material), and $x$ and $y$ are, respectively, the $\mathrm{LaNi}_{5}$ and the $\mathrm{AB}_{3}$-type phase contents.

The effect of the MA duration on the discharge capacities of the active material at the first and the 10th charging-discharging cycle is shown in Fig. 4. This figure shows that the discharge capacity increases up to $20 \mathrm{~h}$ of milling to reach about $156 \mathrm{mAh} / \mathrm{g}$. Above $20 \mathrm{~h}$, the discharge

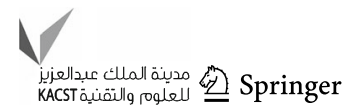




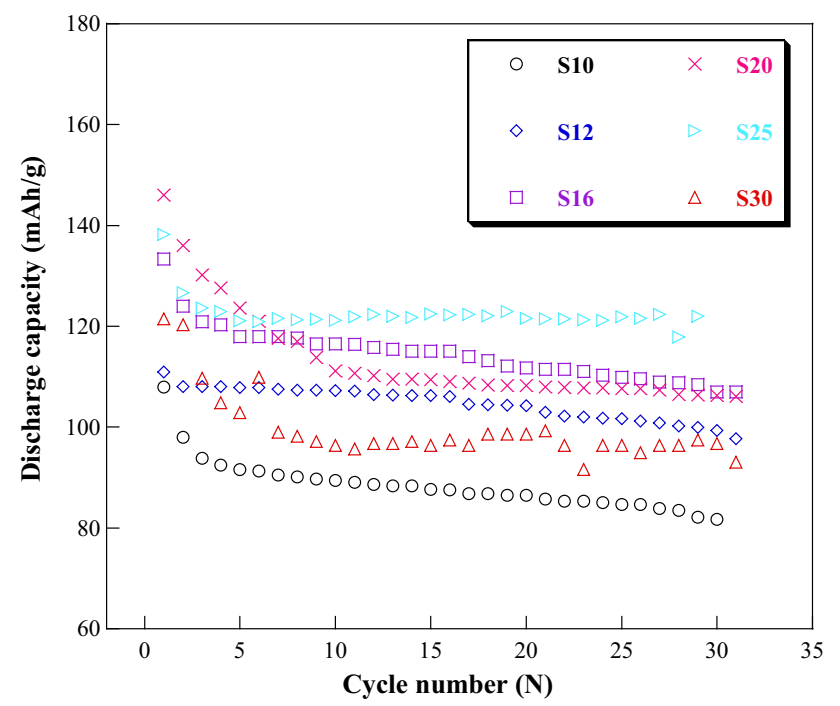

Fig. 3 Variation of the discharge capacity versus cycle number of S10-S30 samples

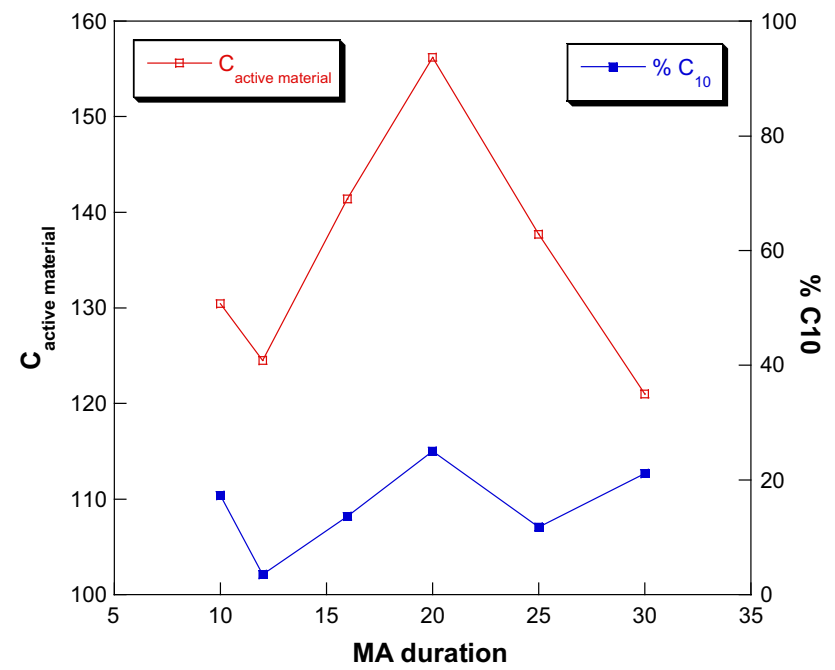

Fig. 4 Effect of MA duration on the dischage capacities of the active material at the first cycle and the loss of discharge capacity at the 10th charging-discharging cycle

capacity decreases with the MA duration to reach values comparable to that obtained at lower milling duration. The storage capacity reduction with the MA duration is attributed to the creation of defects in the material during the synthesis process. During MA, the powder particles which are trapped between the colliding balls are subjected to compressive impact forces. Thus, they are deformed, fractured and cold-welded leading to defects in the system and also an average particle size reduction [19].

As mentioned before, the discharge capacity of $\mathrm{LaCaMgNi}_{9}$ alloy could reach $360 \mathrm{mAh} / \mathrm{g}$ [7] while the maximum discharge capacity obtained in this work is $156 \mathrm{mAh} / \mathrm{g}$ of active material $(146.2 \mathrm{mAh} / \mathrm{g}$ of sample
S20) after $20 \mathrm{~h}$ of MA. In addition, as samples are formed by two hydrogen absorbing phases $\left(\mathrm{LaNi}_{5}\right.$ and $\mathrm{AB}_{3}$-type phase), it is important to know the contribution of each phase to the total discharge capacity. For a polyphasic alloy, the total measured electrochemical discharge capacity would equal to the sum of the contributions of all phases as:

$C_{\text {measured }}(\mathrm{mAh} / \mathrm{g}$ of alloy $)=\sum_{i} x_{i} C_{\phi_{i}}$

where $x_{i}$ and $C_{\phi_{i}}$ are, respectively, the weight content and the electrochemical discharge capacity of the phase $\phi_{i}$. In this work, as mentioned above as only $\mathrm{LaNi}_{5}$ and $\mathrm{AB}_{3}$-type phases are the hydrogen absorbing phases, the total measured electrochemical discharge capacity can be expressed as:

$C_{\text {measured }}(\mathrm{mAh} / \mathrm{g}$ of alloy $)=x \times C_{\mathrm{LaNi}_{5}}+y \times C_{\mathrm{AB}_{3}-\text { typephase }}$

where $x$ and $y$ are, respectively, $\mathrm{LaNi}_{5}$ and $\mathrm{AB}_{3}$-type phase weight contents. $C_{\mathrm{LaNi}_{5}}$ and $C_{\mathrm{AB}_{3}}$ are, respectively, the discharge capacity of $\mathrm{LaNi}_{5}$ and $\mathrm{AB}_{3}$-type phase.

To determine the maximum discharge capacity of the obtained $\mathrm{AB}_{3}$-type phase, we measured the discharge capacity of $\mathrm{LaNi}_{5}$ synthesized in the same energetic condition that the $\mathrm{AB}_{3}$-type one. The obtained value is $180 \mathrm{mAh} / \mathrm{g}$. The discharge capacity of the $\mathrm{AB}_{3}$-type phase is expressed as below:

$C_{\mathrm{AB}_{3} \text {-typephase }}=\left[C_{\text {measured }}-\left(x \times C_{\mathrm{LaNi}_{5}}\right)\right] / y$

Using expression (4), the maximum discharge capacity of the formed $\mathrm{AB}_{3}$-type phase is about $135 \mathrm{mAh} / \mathrm{g}$. Thus, as the discharge capacity of the $\mathrm{LaNi}_{5}$ is higher than that of $\mathrm{AB}_{3}$ type phase, the decrease of the total measured electrochemical discharge capacity or the electrochemical discharge capacity of the active material beyond $20 \mathrm{~h}$ of MA (Fig. 4) is attributed to the decrease of the $\mathrm{LaNi}_{5}$ weight content.

The activation capability is a very important performance for the practical use of Ni-MH battery. It is usually characterized by the number of charge-discharge cycles required to reach the greatest discharge capacity at constant current density. The smaller the number of cycles, the better is the activation performance. The examination of the variation of discharge capacity as function of the cycle number (Fig. 3) reveals that the alloys possess good activation performances, attaining their maximum discharge capacities at the first cycle.

\section{Determination of kinetic parameters of the hydrogen absorption reaction}

Cyclic voltametry Figure 5 shows the cyclic voltammograms for the S30 sample. The working electrode potential 
was scanned from -1.1 to $-0.5 \mathrm{~V}$ versus $\mathrm{Hg} / \mathrm{HgO}(1 \mathrm{~mol} /$ L KOH solution) with scan rates of $10,20,30,40$ and $50 \mu \mathrm{V} / \mathrm{s}$. The anodic and cathodic peaks reflect the information related to the discharge and charge processes [20]. The observed anodic peak is attributed to the oxidation of the desorbed hydrogen atoms at the surface, while the cathodic peak is attributed to the reduction of hydrogen atoms absorbed by the alloy in the interstitial sites. As we can see in Fig. 5, the anodic peak current increases and its potential shifts towards positive direction with increasing scan rate.

Figure 6 gives the variation of the anodic peak potential of the S30 alloy as function of $\log (\mathrm{v})$. This relation is linear. In this case, the anodic peak potential can be written as follows:

$$
\frac{\mathrm{d} E_{\mathrm{ap}}}{\mathrm{d} \log (v)}=\frac{2.3 R T}{2 \alpha n F}
$$

with $R$ is the gas constant, $F$ is the Faraday constant and $T$ is the temperature.

This equation allows the determination of the charge transfer coefficient $\alpha$ (Table 2). This parameter indicates the alloy ability to charge and discharge. As the $\alpha$ value ranges from 0.3 to 0.7 , it can be approximated close to 0.5 [21] which means that the charge and discharge are reversible and the system has the same tendency for the charge as for the discharge process.

Chronoamperometry Figure 7 shows the current responses expressed in $\log (i)$ versus time for the synthesized alloys at $298 \mathrm{~K}$. The semi-logarithmic curves of anode current density versus time can be divided into two time regions. In the first one, the current decreases rapidly due to

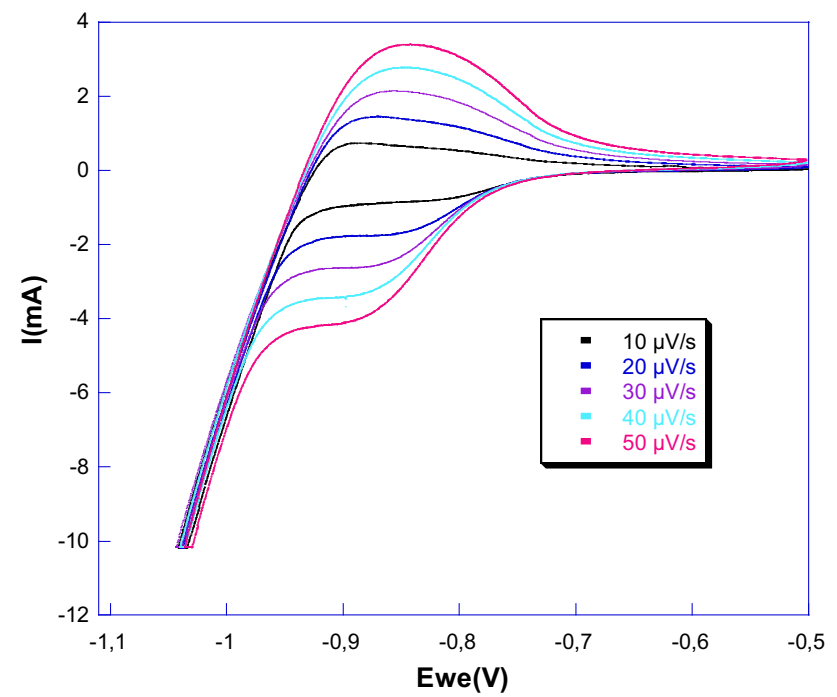

Fig. 5 Cyclic voltammograms of S30 sample at potential scan rate: $10,20,30,40$ and $50 \mu \mathrm{V} / \mathrm{s}$ a consumption of hydrogen at the surface, while in the second time region the current decreases slowly in a linear way. In this case, hydrogen is supplied from the bulk alloy proportionally to the concentration gradient of hydrogen and the current is controlled by the diffusion rate of hydrogen atoms [22] with time [23, 24].

As all samples are multi-phases, the calculated coefficient of hydrogen diffusion is an average value describing the hydrogen diffusion in the whole sample not in a specific phase. From the slope of the linear region in Fig. 7, it is possible to estimate the average coefficient of hydrogen diffusion value using the following formula, which is valid at a large time [23]:

$\log (i)=\log \left(\frac{6 F D}{d a^{2}}\right)\left(C_{0}-C_{\mathrm{s}}\right)-\left(\frac{\pi^{2} D}{2.303 a^{2}}\right) t$

$D=-\frac{2.303 a^{2}}{\pi^{2}} \frac{\mathrm{d} \log (i)}{\mathrm{d} t}$

where $i, D, d, a, C_{0}, C_{\mathrm{s}}$ and $t$ are, respectively, the diffusion current $(\mathrm{A} / \mathrm{g})$, the diffusion coefficient of hydrogen $\left(\mathrm{cm}^{2} / \mathrm{s}\right)$, the density of hydrogen storage, the alloy particle radius $(\mathrm{cm})$, the initial hydrogen concentration in the bulk of alloy $(\mathrm{mol} / \mathrm{cm})$, and the hydrogen concentration on the surface of the alloy particle radius, respectively. Assuming that the average particle radius is $a=5 \mu \mathrm{m}$ (SEM micrograph Fig. 2), $D$ can be calculated according to Eq. (3) and the calculated values are listed in Table 2 . As we can notice, the diffusion coefficient of hydrogen $D$ shows the same behavior than the discharge capacity as a function of MA duration. Its value increases up to $20 \mathrm{~h}$ of MA and decreases for larger time.

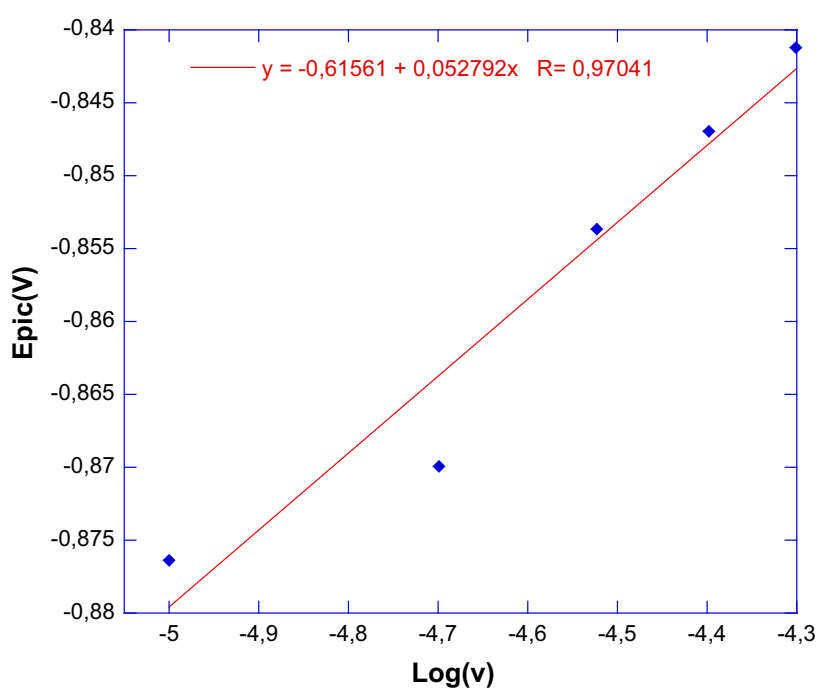

Fig. 6 Variation of the anodic peak potential of cyclic voltammograms of S30 sample as function of $\log (v)$ 
Table 2 Charge transfer coefficient ' $\alpha$ ' and hydrogen diffusion coefficient " $D$ " of the $\mathrm{S} 10-\mathrm{S} 30$ samples

\begin{tabular}{lll}
\hline Sample & $\begin{array}{l}\text { Charge transfer } \\
\text { coefficient ' } \alpha \text { ' }\end{array}$ & $\begin{array}{l}D\left(10^{-10}\right. \\
\left.\mathrm{cm}^{2} / \mathrm{s}\right)\end{array}$ \\
\hline S10 & 0.23 & 4.9 \\
S12 & 0.49 & 5.1 \\
S16 & 0.50 & 6.3 \\
S20 & 0.56 & 6.8 \\
S25 & 0.69 & 6.2 \\
S30 & 0.24 & 5.9 \\
\hline
\end{tabular}

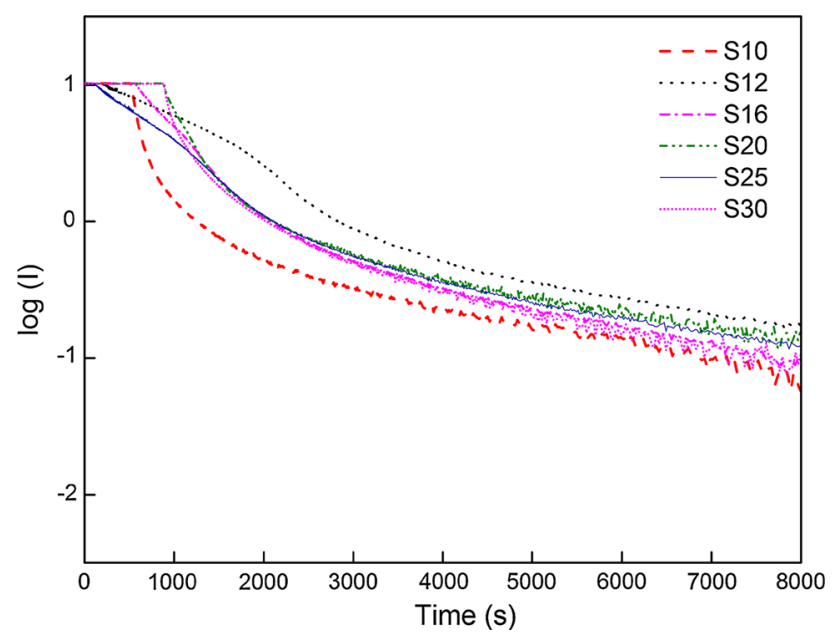

Fig. 7 Semilogarithmic plots of anodic current-time responses of the S10-S30 samples

\section{Conclusion}

A nanostructured $\mathrm{PuNi}_{3}$-type alloy has been synthesized by mechanical alloying of a stoichiometric mixture of $\mathrm{La}, \mathrm{Ca}$, $\mathrm{Mg}$ and $\mathrm{Ni}$ elements at different milling duration. The electrochemical properties of the milled samples have been investigated by electrochemical methods: chronopotentiometry, cyclic voltammetry and chronoamperometry. The following conclusions can be drawn:

All samples exhibit limited discharge capacity with a maximum of about $156 \mathrm{mAh} / \mathrm{g}$ after $20 \mathrm{~h}$ of MA. Further, the discharge capacity decreases with increasing MA duration. This is attributed to the increase of lattice defects and the decrease of particle size.

The values of the charge transfer coefficient range from 0.3 to 0.7 for samples mechanically alloyed between 12 and $25 \mathrm{~h}$ which indicate a good reversibility of the electrochemical reaction. For the sample milled for 10 and $30 \mathrm{~h}$, the $\alpha$ values are, respectively, 0.232 and 0.242 .

\section{Highlights}

- Synthesis of $\mathrm{LaCaMgNi}_{9}$-type alloy by mechanical alloying.

- Effect of increasing MA duration on the electrochemical properties of the obtained alloy.

- ' $\alpha$ ' values range from 0.3 to 0.7 .

- ' $D$ ' and the discharge capacity have the same behavior as function of MA duration.

Acknowledgments The financial support was guaranteed by the CMCU project (CMCU PHC Utique $\mathrm{N}^{\circ} 10 \mathrm{G} 1208$ ).

Open Access This article is distributed under the terms of the Creative Commons Attribution 4.0 International License (http:// creativecommons.org/licenses/by/4.0/), which permits unrestricted use, distribution, and reproduction in any medium, provided you give appropriate credit to the original author(s) and the source, provide a link to the Creative Commons license, and indicate if changes were made.

\section{References}

1. Barghi, S.H., Tsotsis, T.T.: Chemisorption, physisorption and hysteresis during hydrogen storage in carbon nanotubes. Int $\mathrm{J}$ Hydrogen Energy 39, 1390-1397 (2013)

2. Rogulski, Z., Diubak, J., Karwowska, M., Pytlik, E.: Studies on metal hydride electrodes containing no binder additives. J Power Sour 195, 7517-7523 (2010)

3. Li, S., Zhao, M., Wang, L., Liu, Y., Wang, Y.: Structures and electrochemical characteristics of $\mathrm{Ti}_{0.2} 6 \mathrm{Zr}_{0.07} \mathrm{~V}_{0.24} \mathrm{Mn}_{0.1} \mathrm{Ni}_{0.33}$ Mox $(x=0-0.1)$ hydrogen storage alloys. Mater Sci Eng B 150, 168-174 (2008)

4. Mu, D., Hatano, Y., Abe, T., Watannabe, K.: Degradation kinetics of discharge capacity for amorphous $\mathrm{Mg}-\mathrm{Ni}$ electrode. J alloys Compd 334, 232-237 (2002)

5. Young, K., Nei, J., Huang, B., Fetcenko, M.A.: Studies of offstoichiometric $\mathrm{AB}_{2}$ metal hydride alloy: part 2. Hydrogen storage and electrochemical properties. Int $\mathrm{J}$ Hydrogen Energy 36, 11146-11154 (2011)

6. Miyamura, H., Sakai, T., Kuriyama, N., Oguro, K., Kato, A.: Hydrogen storage materials, batteries and electrochemistry. In: Electrochemical Society Proceedings, vol. 92-5, pp 179-198 (1992)

7. Chen, J., Kuriyama, N., Takeshita, H.T., Tanaka, H., Sakai, T.: Hydrogen storage alloys with PuNi3-type structure as metal hydride electrodes. Electrochem Solid State Lett 3(6), 249-252 (2000)

8. Pan, H.G., Liu, Y.F., Cao, M.X., Zhv, Y.F., Lei, Y.Q., Wang, Q.D.: An investigation on the structural and electrochemical properties of $\mathrm{La}_{0.7} \mathrm{Mg}_{0.3}\left(\mathrm{Ni}_{0.85} \mathrm{Co}_{0.15}\right)_{\mathrm{x}}(x=3.15-3.80)$ hydrogen storage electrode alloys. J Alloys Compd 351, 228-234 (2003)

9. Liao, B., Li, Y.Q., Chen, L.X., Lu, G.L., Pan, H.G.: A study on the structure and electrochemical properties of $\mathrm{La}_{2} \mathrm{Mg}\left(\mathrm{Ni}_{0.95}\right.$ $\left.\mathrm{M}_{0.05}\right)_{9}(\mathrm{M}=\mathrm{Co}, \mathrm{Mn}, \mathrm{Fe}, \mathrm{Al}, \mathrm{Cu}, \mathrm{Sn})$ hydrogen storage electrode alloys. J Alloys Compd 376, 186-195 (2004)

10. Pan, H.G., Liu, Y.F., Gao, M.X., Lei, Y.Q., Wang, Q.D.: Electrochemical Properties of the $\mathrm{La} 0.7 \mathrm{Mg} 0.3 \mathrm{Ni} 2.65-\mathrm{x}$ Mn0.1Co0.75Al x $(x=0-0.5)$ Hydrogen storage alloy electrodes. J Electrochem Soc 152(2), A326-A332 (2005) 
11. Kadir, K., Sakai, T., Uehara, I., Kadir, K., Sakai, T., UeharaI, I.: Structural investigation and hydrogen capacity of $\mathrm{YMg}_{2} \mathrm{Ni}_{9}$ and $\left(\mathrm{Y}_{0.5} \mathrm{Ca}_{0.5}\right)(\mathrm{MgCa}) \mathrm{Ni}_{9}$ : new phases in the $\mathrm{AB}_{2} \mathrm{C}_{9}$ system isostructural with $\mathrm{LaMg}_{2} \mathrm{Ni}_{9}$. J Alloys Compd 287, 264-270 (1999)

12. Kadir, K., Sakai, T., Uehara, I.: Structural investigation and hydrogen storage capacity of $\mathrm{LaMg}_{2} \mathrm{Ni}_{9}$ and $\left(\mathrm{La}_{0.65} \mathrm{Ca}_{0.35}\right)(-$ $\left.\mathrm{Mg}_{1.32} \mathrm{Ca}_{0.68}\right) \mathrm{Ni}_{9}$ of the $\mathrm{AB}_{2} \mathrm{C}_{9}$ type structure. $\mathrm{J}$ Alloys Compd 302, 112-117 (2000)

13. Chebab, S., Abdellaoui, M., Latroche, M., Paul-Boncour, V.: Structural and hydrogen storage properties of $\mathrm{LaCaMgNi}_{9}$-type alloy obtained by mechanical alloying. Mater Renew Sust Energy, in press, (2015). http://dx.doi.org/10.1007/s40243-0150053-x

14. Joseph, B., Iadecola, A., Schiavo, B., Cognigni, A., Olivi, L.: Local structure of ball-milled $\mathrm{LaNi}_{5}$ hydrogen storage material by Ni K-edge EXAFS. J Solid State Chem 183, 1550 (2010)

15. Joseph, B., Schiavo, B.: Effects of ball-milling on the hydrogen sorption properties of $\mathrm{LaNi}_{5}$. J Alloys Compd 480, 912 (2009)

16. Rietveld, H.M.: Line profiles of neutron powder-diffraction peaks for structure refinement. Acta cristallgr 22, 151 (1967)

17. Rietveld, H.M.: A profile refinement for nuclear and magnetic structures. J Appl Cryst 2, 65 (1969)
18. Rodriguez-Carvajal, J.: Recent advances in magnetic structure determination by neutron powder diffraction. J Phys 192B, 55 (1993)

19. Wu, Y., Hana, W., Zhou, S.X., Lototsky, M.V., Solberg, J.K., Yartys, V.A.: Microstructure and hydrogenation behavior of ballmilled and melt-spun $\mathrm{Mg}-10 \mathrm{Ni}-2 \mathrm{Mm}$ alloys. J. Alloys Compd 466, 176 (2008)

20. Tan, Z., Yang, Y., Li, Y., Shao, H.: The performances of $\mathrm{La}_{1--}$ $x$ Cex $\mathrm{Ni}_{5}(0 \leq x \leq 1)$ hydrogen storage alloys studied by powder microelectrode. J Alloys Compd 453, 79-86 (2008)

21. Bard, A.J., Fulkner, L.R.: Electrochimie: Principe, Methodes and Applications. Masson, Paris (1998)

22. Giza, K.: Electrochemical studies of $\mathrm{LaNi}_{4.3} \mathrm{Co}_{0.4} \mathrm{Al}_{0.3}$ hydrogen storage. Intermetallics 34, 128-131 (2013)

23. Zheng, G., Popov, B.N., White, R.E.: Electrochemical determination of the diffusion coefficient of hydrogen through an $\mathrm{LaNi}_{4.25} \mathrm{Al}_{0.75}$ electrode in alkaline aqueous solution. J Electrochem Soc 142, 2695 (1995)

24. Pan, H., Chen, N., Gao, M.: Effects of annealing temperature on structure and the electrochemical properties of $\mathrm{La}_{0.7} \mathrm{Mg}_{0.3} \mathrm{Ni}_{2.45}$ $\mathrm{Co}_{0.75} \mathrm{Mn}_{0.1} \mathrm{Al}_{0.2}$ hydrogen storage alloy. J Alloys Compd 397, 306 (2005) 